\title{
Livros escolares e ensino de escrita: selecionando material entre a linguística e a história $^{1}$
}

\author{
Cristian Henrique Imbruniz ${ }^{2}$
}

Resumo: Este artigo defende que dados editoriais de livros escolares são enunciados em ruína. Seu estado de ruína, ao invés de excluí-los do horizonte da pesquisa, permite uma articulação entre análise do discurso francesa e história. Considerada a operação historiográfica (DE CERTEAU, 1982), pode-se, assumindo a posição do analista de discurso, conceber o livro escolar como parte de um acontecimento discursivo (PÊCHEUX, 2015). Os dados em ruína seriam enunciados que se entrecruzam no encontro de uma atualidade e de uma memória. Exemplificando esse procedimento, analiso o Método de redação, de Carlos Góes (1930).

Palavras-chave: Livro escolar. Ensino de escrita. Acontecimento discursivo. Operação historiográfica.

Abstract: This article argues that schoolbook publishing data are utterances in ruin. Its state of ruin, instead of excluding them from the horizon of research, allows an articulation between French discourse analysis and history. Considering the historiographic operation (DE CERTEAU, 1982), one can assume the position of the discourse analyst to conceive the schoolbook as part of a discursive event (PÊCHEUX, 2015). The data in ruin would be utterances that intersect in the meeting of a current and a memory. In order to exemplify this procedure, I analyze the Método de redação, by Carlos Góes (1930).

Keywords: Schoolbook. Teaching write. Discursive event. Historiographic operation.

Résumé: Cet article soutient que les données de publication de livres scolaires sont enoncés en ruine. Leur état de ruine, au lieu de les exclure de l'horizon de la recherche, permet une articulation entre l'analyse du discours française et l'histoire. Considérant l'opération historiographique (DE CERTEAU, 1982[1974]), on peut supposer la position de l'analyste du discours pour concevoir le livre scolaire comme faisant partie d'un événement discursif (PÊCHEUX, 2015). Les données en ruine seraient des énoncés qui se croisent dans la rencontre d'un courant et d'une mémoire. En illustrant cette procédure, j’analyse le Método de redação, de Carlos Góes (1930).

Mot-clés: Livre scolaire. Enseignement de l'écriture. Discursive évenement. Opéracion historiographique.

\footnotetext{
${ }^{1}$ Agradeço à FAPESP pelo financiamento, processo n 2017/24562-9, Fundação de Amparo à Pesquisa do Estado de São Paulo (FAPESP).

${ }^{2}$ Mestrando em Filologia e Língua Portuguesa pela Universidade de São Paulo.
}

Este artigo está licenciado sob forma de uma licença Creative Commons Atribuição 4.0 Internacional, que permite uso irrestrito, distribuição e reprodução em qualquer meio, desde que a publicação

original seja corretamente citada. https://creativecommons.org/licenses/by/4.0/deed.pt BR. 


\section{Introdução ${ }^{3}$}

Uma das maneiras de se abordar o ensino de escrita é, em sala de aula, perseguir suas práticas, observando as interações entre alunos e professores e, também, as diferentes estratégias utilizadas por estes últimos para expor o conteúdo a ser ensinado. Para esse tipo de estudo, uma abordagem etnográfica pode ser a mais adequada. No entanto, ao tomar o livro didático de português como objeto, situo-me em outro lugar, o da linguística aplicada, mais especificamente, o da perspectiva discursiva no campo da linguística aplicada. Portanto, mais do que situar a pesquisa no campo da etnologia, situo-a no ponto de encontro entre a linguística e a história.

Note-se, apesar disso, que a etnologia tem uma relação estreita com a história. Para De Certeau (1982 [1974], p. 92-93), a etnologia troca, parcialmente, lugares com a história para instaurar, no presente, uma “encenação do outro”. A relação está no fato de que o passado, se tomado como objeto da história, representa, do mesmo modo que o presente à luz da etnologia, uma encenação do outro por meio da historicização da situação vivida. Entretanto, é preciso acentuar que a troca de papéis de que fala De Certeau é parcial. Para ele, a operação historiográfica tem um efeito duplo. Por um lado, historiciza o atual, mais especificamente, "presentifica uma situação vivida” (DE CERTEAU, 1982 [1974], p. 93). Por outro, e aí, segundo penso, está sua particularidade, representa aquilo que falta.

O segundo efeito da operação historiográfica, a representação de uma ausência, justifica minha escolha pela articulação entre a linguística e a história. Ao invés de instaurar o outro no presente, pretendo, com o estudo de livros escolares de português, perseguir essa ausência na qual repousa o não dito.

Para quem foi aluno nos últimos 30 anos, tempo de atividade mais estável do Programa Nacional do Livro Didático (PNLD), pode ser difícil não associar o livro didático a uma presença familiar na escola. No entanto, os discursos que garantem essa

\footnotetext{
${ }^{3}$ Agradeço à professora Maurilane Biccas, que, na disciplina História da educação: arquivos e fontes, ministrada no $1^{\circ}$ semestre de 2018, junto ao Programa de Pós-Graduação em Educação, na Faculdade de Educação da Universidade de São Paulo, propôs a discussão de $A$ operação historiográfica, de Michel de Certeau. Uma primeira versão deste artigo foi entregue como trabalho final dessa disciplina.
} 
familiaridade são heterogêneos. Dentre outras coisas, passam pelas políticas públicas, pelo mercado editorial e, mais importante, pelos próprios livros didáticos e sua história, neste trabalho restrita a um período recente (fim da primeira metade do séc. XX e passagem para o séc. XXI).

Em dissertação de mestrado em andamento, proponho-me a analisar um conjunto de livros escolares de português, em especial suas seções de ensino de escrita, que recobre o período de 1930 a 2002, ou seja, um recorte de 72 anos. Para tornar esse recorte temporal operacionalizável em termos de seleção de material, elegi dois critérios: (1) autoral-editorial; e (2) linguístico-discursivo; com base nos quais selecionei, de cada década iniciada, dois livros didáticos de português, totalizando dezesseis deles por meio do critério (1) e, dentre esses, oito, por meio do critério (2). $\mathrm{O}$ objetivo do presente trabalho é mostrar como a fundamentação teórico-metodológica atua desde o primeiro momento da pesquisa. Para tanto, detenho-me no primeiro critério, o autoral-editorial.

Em princípio, para o critério autoral-editorial, importariam dados de circulação dos livros didáticos publicados em cada década, o que, da exterioridade da obra, acaba por manter relação direta com questões de ordem linguístico-discursiva, consideradas no segundo critério. Grosso modo, para selecionar os livros escolares de maior relevância em cada década, seria preciso responder quais deles tiveram o maior número de reedições, reimpressões e, também, quais foram os autores e casas editoriais mais influentes. As primeiras consultas aos documentos, sejam aos da Fundação Biblioteca Nacional, aos do acervo da Companhia Editora Nacional ou aos do Instituto Nacional de Estudos e Pesquisas Educacionais (INEP), sejam aos produzidos como parte das políticas públicas governamentais, revelaram a ausência de um registro regular e, portanto, a impossibilidade de responder aos problemas do critério autoraleditorial.

Reiterando, em função desse problema, o objetivo deste trabalho, ao explorar a relação entre linguística e história, pretendo fixar algumas bases teóricas que permitam aplicar o critério autoral-editorial. Primeiramente, tomando emprestada a expressão de Corrêa (2006b), aplicada à relação entre gêneros discursivos, considero, como parte 
genuína dos documentos, os dados editoriais em estado de ruína ${ }^{4}$. Na tentativa de defender essa ideia, apresento a discussão de De Certeau (1982[1974]) sobre a operação historiográfica, na qual, a meu ver, o autor se aproxima da análise do discurso francesa, sobretudo das noções de formação discursiva (PÊCHEUX, 2014[1975]) e de acontecimento discursivo (PÊCHEUX, 2015; GUILHAUMOU; MALDIDIER, 2014[1986]). Apresento, em seguida, um livro escolar de 1930, o Método de Redação com gramática aplicada, de Carlos Góes.

Tomando esse livro como exemplo, busco observar a sua produção e circulação segundo seus dados editoriais, mesmo sendo eles lacunares no que se refere, por exemplo, à quantidade de edições e reimpressões. Dados lacunares podem ganhar consistência de fato discursivo quando considerada a relação entre produção e circulação, incluindo, nesta última, por onde determinado livro circula e para quem se dirige. Melhor dizendo, a relação entre as instâncias de produção/destinação/circulação tem a natureza de um acontecimento discursivo, o que permite atribuir historicidade a um artefato, o próprio livro, sem que ele próprio seja identificado com o acontecimento. Desse modo, visto na instância de partida (produção) ou na de chegada (destinação), determinado livro é apenas uma parte dessa relação, mas se situa e se historiciza na relação estabelecida entre essas instâncias, isto é, no acontecimento discursivo de sua emergência, o qual não corresponde apenas ao momento de seu surgimento, mas, também, ao tempo de sua permanência 5 .

\footnotetext{
${ }^{4}$ Sobre o empréstimo que faço de Corrêa (2006b) do termo ruína, embora compartilhe com o autor o mesmo horizonte teórico e, parcialmente, o mesmo objetivo com a aplicação do conceito de ruína, utilizo-o em dados de natureza diversa daqueles a partir dos quais esse conceito foi, originalmente, concebido. Em Corrêa, as ruínas de gêneros discursivos são, considerada a característica dialógica da linguagem, uma resposta à impossibilidade de classificação de referências textuais precisas, geralmente entendidas como fontes de uma réplica fundadora, ligada ao "modo pelo qual os vestígios de gêneros discursivos - enunciados tomados como réplicas - aparecem" (CORRÊA, 2006b, p. 209). Assumindo o dialogismo (BAKHTIN, 2016 [1978]) como posição teórica, as ruínas são uma forma de, a partir fatos textuais-discursivos, detectar relações intergenéricas, uma vez que "tais ruínas são partes mais ou menos informes de gêneros discursivos que, quando presentes em outro gênero, ganham o estatuto de fontes históricas - retrospectivas ou prospectivas - da constituição de uma fala ou de uma escrita" (CORRÊA, 2006b, p. 209). Para tratar de dados editoriais lacunares, interessamme, do conceito de Corrêa, três coisas: (1) a ênfase no aspecto positivo de um dado (textualdiscursivo ou não) cujas origens não podem ser "descritas, datadas e classificadas como fundadoras" (CORRÊA, 2006b, p. 209), o que, ao evitar sua acepção negativa - como "dados em estado destruição" -, privilegia sua eficácia como fonte histórica; (2) a sua capacidade de marcar um aspecto singular do dialogismo em determinados enunciados; e (3) seu aspecto mais ou menos informe, do qual me aproprio, acrescentando o sentido de lacunosidade, próprio aos dados que trato neste artigo. Agradeço a Michele Siqueira pelos comentários.

${ }^{5}$ Agradeço a sugestão dada pelo professor Manoel Corrêa.
} 


\section{O que digo que faço e o que digo do que faço}

O jogo de palavras, sugerido por De Certeau (1982 [1974], p. 66), levanta, ao menos, uma questão importante: os princípios que orientam uma determinada prática (o que digo que faço) são os mesmos quando o seu objeto é a própria prática (o que digo do que faço)? Considerando que o gesto que liga as ideias aos lugares é o gesto do historiador, De Certeau se questiona se seria possível fugir à evidência, no caso de a própria história ser o objeto de reflexão, de que, como outros sistemas de pensamento, a história é produto de um lugar. Para ele, a evidência se impõe. Ao escrever sobre a história, o historiador escreve de um lugar social, do mesmo modo que o faz ao escrever sobre outros objetos, uma vez que se trata do mesmo gesto que liga as ideias aos lugares. Com isso, De Certeau reconhece que a dicotomia que opõe "o que se faz" a "o que se diz do que se faz" distancia a história de sua prática efetiva, deslocando-a para uma verdade fora da própria história, que a faria pressupor valores eternos (entendidos, aqui, como teoria e metodologia), válidos apenas para alguns de seus objetos, mas nunca para a sua própria prática.

Afastando o "sonambulismo teórico" (DE CERTEAU, 1982 [1974], p. 66) a que poderia ser conduzida a prática do historiador, De Certeau mostra que, para encarar a história como uma operação, deve-se combinar um lugar social, práticas científicas e uma escrita. A propósito da mediação das atividades técnicas inerentes a essa operação, o autor questiona o que chama de enigmática relação com a sociedade presente e com a morte.

Para De Certeau (1982 [1974], p. 66), toda pesquisa historiográfica se articula com um lugar de produção. Nele, há implicações socioeconômicas, políticas e culturais. A escrita da história não está, portanto, livre de imposições. Ao contrário, ela está situada num particular. A título de exemplo, pode-se pensar no cientificismo histórico. Com a crítica inaugural ao chamado cientificismo, feita por Raymond Aron, 
constatou-se a relação da história com um lugar, o do sujeito. A objetividade da história estava, pois, questionada:

Mostrou-se que toda interpretação histórica depende de um sistema de referência; que este sistema permanece uma "filosofia" implícita particular; que infiltrando-se no trabalho de análise, organizando-o à sua revelia, remete à "subjetividade" do autor (DE CERTEAU, 1982 [1974], p. 67).

Diferentemente do que pensa Aron, essa constatação, instaurada por ele como desconfiança, não livra a história de um lugar social, pois o pertencimento a um lugar social é a condição de existência de todos os sistemas de pensamento, inclusive da história. Valendo-se da distinção proposta por Weber entre o sábio e o político, segundo De Certeau (1982 [1974], p. 68), uma das mais questionáveis de sua obra, Aron reforçava o poder de isenção dos sábios, de modo que, ao deslegitimar o lugar da subjetividade, instaura um outro, o de um produto, isto é, um lugar supostamente livre de interferência do sujeito, pois, ausente essa interferência, o historiador estaria no reino das decisões individuais sob o fundo de uma totalidade da história.

Nesse sentido, a tentativa de expurgar o lugar da subjetividade leva a um tipo de cristalização das práticas. Ainda de acordo com De Certeau (1982 [1974], p. 68), o retorno às decisões pessoais da relatividade histórica tinha dois postulados que caminhavam juntos: o primeiro, isolar o elemento filosófico do texto historiográfico visando a uma autonomia para a ideologia; o segundo, destacar a divergência entre os filósofos e os historiadores, fazendo dos filósofos um grupo isolável da sociedade em função de uma suposta relação direta com o pensamento. Desse modo, reserva-se uma posição singular para os intelectuais:

Sendo as questões de sentido tratadas entre eles, a explicitação de suas diferenças de pensamento equivalia a gratificar o grupo inteiro com uma relação privilegiada com as idéias. Nada dos ruídos de uma fabricação, de técnicas, de imposições sociais, de posições profissionais ou políticas perturbava a paz desta relação: um silêncio era o postulado desta epistemologia (DE CERTEAU, 1982 [1974], p. 68).

A propósito do lugar social, é preciso destacar o papel da instituição do saber. Segundo o mesmo autor, de Bacon a Descartes, a instituição do saber aparece como 
“despolitização dos sábios” (DE CERTEAU, 1982 [1974], p. 69). Mas De Certeau (1982 [1974], p. 69) afirma não se poder entender esse processo como ausência de um lugar, conforme procurou mostrar com a crítica a Aron. Trata-se mais da particularização de um lugar específico. Da mesma maneira que se confere aos assuntos públicos e aos assuntos religiosos um lugar, estabelece-se um lugar "científico" para a matéria científica. Em outras palavras, "um lugar articulado sobre outros num conjunto novo, e através de sua face interna, a instauração de um saber indissociável de uma instituição social" (DE CERTEAU, 1982 [1974], p. 69).

Da constatação, por Aron, do lugar da subjetividade na escrita da história e do papel destacado da instituição do saber, percebe-se que o que se chama ciência remete a um estatuto social que é o seu não dito. Embora oculto, ele fala. É em função disso que se pode afirmar que o lugar social no qual se constitui uma disciplina, no caso, a história, permite e interdita discursos. Essa dupla função destacada por De Certeau (1982 [1974], p. 76-77) torna possíveis certas pesquisas ao mesmo tempo em que torna outras impossíveis. Para ele, esse é o ponto cego da pesquisa histórica e o que a diferencia, por exemplo, da lenda. Do mesmo modo, é preciso olhar para essa dupla função para agir sobre ela e, acrescento, operacionalizá-la como procedimento teórico. Pode-se pensar, portanto, a história como uma operação do discurso entre o que é permitido e o que é interditado.

\section{A feitura da escrita da história}

É possível tomar a história como uma prática que se desenrola na articulação entre a cultura e a natureza. As técnicas da história estão situadas justamente nessa articulação, de modo que, "colocando-se ao nível desta prática, não mais se encontra a dicotomia que opõe o natural ao social, mas a conexão entre uma socialização da natureza e uma 'naturalização' (ou materialização) das relações sociais" (DE CERTEAU, 1982 [1974], p. 79, grifos do autor). 
Não considerar essa articulação conduz o historiador ao problema da narratividade "pura". Ignorando o trabalho de socialização da natureza e materialização das relações sociais, toma-se o passado como um artefato acabado. Nesse caso, deixa-se de ser historiador e, abandonando a prática (e também a teoria), torna-se apenas um consumidor desse produto. Os objetos do passado são recebidos como sentidos inequívocos. Na contramão, ao defender a história como prática, De Certeau (1982 [1974], p. 80) chama de científica a operação que transforma o documento em objeto. A operação historiográfica, ao instaurar o que o autor chama de governo da natureza, faz da relação do presente com o passado não um dado, mas um objeto a ser elaborado e, portanto, situado no plano do equívoco.

Por isso, o primeiro gesto do historiador seria o de separar e transformar os documentos. Mais do que isso, o primeiro gesto seria o de produzir os documentos. Segundo De Certeau (1982 [1974], p. 81), o universo do uso é transformado com ações combinadas que, necessariamente, remetem a uma operação técnica. Em outras palavras, pode-se dizer que a prática da história é, dentre outras possibilidades, a transformação de um conjunto de documentos, cujo uso já estava consolidado em um tempo e um espaço determinados, em outra coisa. Ainda sobre isso, ao se referir a documentos comumente deixados de lado (seria o caso dos livros escolares), o autor chama a atenção para o fato de que não se trata de "dar voz a um silêncio" (DE CERTEAU, 1982 [1974], p. 82-83), mas de conceber um novo objeto pela transformação, seja ele pouco ou muito utilizado, próprio à prática do historiador e ao lugar ao qual ela está circunscrita. A prática científica é, pois, de redistribuição do espaço a partir do lugar do qual a história é escrita.

\section{A escrita da história}

A escrita só é histórica na medida em que se liga, institucional e tecnicamente, ao lugar social de uma operação científica e a uma prática. Pode-se dizer, portanto, uma vez mais, que a operação historiográfica é composta por um lugar social, uma 
prática e um gesto de escritura. A respeito da escrita, De Certeau lembra que, mais do que controlada pela prática, ela mesma é uma prática social e, por isso, confere ao leitor um lugar, "redistribuindo o espaço das referências simbólicas e impondo, assim, uma 'lição'; ela é didática e magisterial” (DE CERTEAU, 1982 [1974], p. 95).

Sendo uma prática ela mesma, a função da escrita é complementar à função da prática histórica. Segundo De Certeau (1982 [1974], p. 107), ela representa um rito de

sepultamento e cumpre uma função simbolizadora em relação ao passado. É nesse sentido que o autor afirma que a linguagem permite à prática uma relação com o seu outro, isto é, uma relação com o passado.

Tomando a história como objeto de reflexão, De Certeau não se preocupa com o destino ou as possibilidades de uma "ciência objetiva". Na verdade, busca meios para jogar luz ao fato de que a relação com a linguagem é uma relação com a morte e o discurso histórico é, pois, o que o próprio autor concebe como uma representação privilegiada de uma ciência do sujeito que, dividido, revela as representações das relações que um corpo social mantém com sua linguagem.

\section{Aproximações entre história e análise do discurso francesa}

Ao escrever sobre a operação historiográfica, De Certeau não se esquiva das questões de linguagem. Muito pelo contrário, toma-as como parte do seu próprio problema. Para ele, o discurso histórico é uma instância privilegiada de observação da relação que um corpo social mantém com a (sua) linguagem. Ao considerar a história como uma operação, consciente das exigências desse procedimento, recorre à língua e à linguagem não como ferramentas, mas como reflexão decisiva, sobretudo no que diz respeito à escrita da história e ao seu lugar social.

No caso da escrita da história, destaca-se, por exemplo, a questão do deslizamento metafórico. De Certeau (1982 [1974], p. 101) argumenta que o discurso histórico está entre o discurso narrativo e o discurso lógico, pois oferece um conteúdo verificável do ponto de vista lógico, mas na forma de uma narrativa. O trânsito entre 
esses tipos de discurso, ainda segundo o autor, não consegue ocultar o deslizamento metafórico dos procedimentos geradores do texto.

No caso do lugar social da escrita da história, destaca-se a instância que permite e interdita discursos. Trata-se de um problema de linguagem que se relaciona com a história e com o inconsciente, muito próximo das preocupações da análise do discurso francesa, na medida em que pode ser transformado numa pergunta mais elementar: o que pode e deve ser dito num dado lugar social?

Detendo-me no lugar social da escrita da história, gostaria de explorar, em um primeiro momento, a sua relação com o conceito de formação discursiva (PÊCHEUX, 2014 [1975], p. 147). Penso que essa aproximação teórica permita evidenciar um espaço comum às duas disciplinas no que diz respeito ao tratamento teórico-metodológico dos seus objetos. É nesse espaço que gostaria de situar esta pesquisa, isto é, entre a língua e a história, ou seja, no campo do particular e, portanto, do discurso (COURTINE, 2014 [1981]).

Já situado nesse espaço, recorro ao que Pêcheux (2010 [1969], p. 72) afirma sobre a normalidade do enunciado. $\mathrm{O}$ autor questiona a validade de uma norma universal para determinar a qualidade de normal ou de anômalo de um enunciado. Reitera, ainda, que é preciso questionar a identidade que Saussure estabeleceu entre o universal e o extrauniversal. Pêcheux defende a existência de um nível intermediário entre a singularidade individual e a universalidade, o particular. Esse nível “define 'contratos' linguísticos específicos de tal ou tal região do sistema, isto é, feixes de normas mais ou menos localmente definidos, e desigualmente aptos a disseminarem-se uns sobre os outros" (PÊCHEUX, 2010 [1969], p. 72). A articulação entre a linguística e a história, nos termos em que a exploro, só funcionaria no nível da particularidade, dos contratos mais ou menos localmente definidos, pois, em primeiro lugar, ele é a própria condição de possibilidade da articulação e, em segundo, porque é do particular e sobre o particular que falam Pêcheux e De Certeau.

Em outras palavras, acredito que De Certeau e Pêcheux produzem, a partir da história ou a partir da linguística, referências a um particular, de tal maneira que a atenção de ambos os autores a modos de conhecimento dos campos da própria história, do discurso e da psicanálise aproxima-os de uma região epistemológica 
comum ao definirem o particular. Acredito que essa definição permite, portanto, aproximar os dois autores, não só articulando as suas diferentes propostas, mas também reclamando o domínio do particular para a prática de pesquisa de que me ocupo: uma análise linguístico-discursiva de oito livros escolares produzidos no período entre 1930 e 2002. A propósito, a objeção de que De Certeau poderia não compreender esse particular de modo expansível (para fora da operação historiográfica) não está em questão nesta retomada, já que importa apenas destacar que "toda pesquisa historiográfica se articula com um lugar de produção socioeconômico, político e cultural" (DE CERTEAU, 1982 [1974], p. 66). No restrito percurso historiográfico que efetuo, é a esse particular que remeto a apreensão dos livros escolares e sua leitura.

Ao instaurar a desconfiança do lugar do sujeito na escrita da história, Aron ensinou a uma geração as técnicas para detectar a presença de uma filosofia subjacente nos trabalhos de historiadores, isto é, o traço individual do historiador na escrita da história. A esse ensinamento, De Certeau (1982 [1974], p. 68) acrescenta uma crítica: ao mesmo tempo que, supostamente, o ensinamento de Aron explicita a presença de uma subjetividade, teria, como sobra indesejável para o historiador, nos termos de Weber conforme foi mobilizado pelo próprio Aron, a isenção do sábio. Reforçando a isenção, Aron "estabeleceu um estatuto reservado tanto para o reinado das ideias quanto para o reinado dos intelectuais”. Desse modo, De Certeau critica a autonomia do lugar teórico, que substitui "o privilégio silencioso de um lugar por aquele outro, triunfante e discutível, de um produto" (DE CERTEAU, 1982 [1974], p. 68). Nesse caso, o lugar da história (incontornável!) seria, portanto, o de um produto, mesmo que o objetivo de Aron fosse chegar à ausência completa de "lugares" que pudessem atuar na escrita da história.

De modo semelhante a De Certeau (1982 [1974]), embora este último situe suas observações no campo de uma operação epistemológica e, nesta, se restrinja ao trabalho do historiador no campo (epistemológico) da operação historiográfica, Pêcheux, não fugindo à reflexão epistemológica por meio da qual situa a teoria do discurso em relação aos impensados das teorias linguísticas que o antecederam, referese à língua como base de processos discursivos, chamando, a seu modo, a atenção para 
a necessidade de situar o sentido (em geral) numa posição/lugar. Para ele, "as palavras, expressões, proposições etc., mudam de sentido segundo as posições sustentadas por aqueles que as empregam, o que quer dizer que elas adquirem seu sentido em referência a essas posições" (PÊCHEUX, 2014 [1975], p. 146-147, grifo do autor). Em Pêcheux, é a partir da delimitação dessa posição que se pode pensar o conceito de formação discursiva. Ela é o que pode e deve ser dito numa certa posição e numa certa conjuntura, determinadas pelo estado da luta de classes. Considerada essa função de permitir o que pode e deve ser dito, é possível pensar, simetricamente, que a formação discursiva, do mesmo modo que o lugar social da escrita da história, permite e interdita o sentido. É por isso que, para Pêcheux (2014 [1975], p. 147), "as palavras, expressões, proposições etc., recebem seu sentido da formação discursiva na qual são produzidas".

Embora Pêcheux e De Certeau não compartilhem integralmente a tradição de pensamento em que se situam, nem mesmo suas conclusões, chama a atenção a sua proximidade. A conceptualização da produção/apreensão de um sentido particular por meio da dupla função de interdição e de permissão de um lugar/posição, seja na linguagem em geral, seja na escrita da história, ponto de articulação teórica entre os dois autores, serve para evidenciar um dos propósitos deste trabalho: o de que tanto De Certeau quanto Pêcheux falam do e no particular, região onde também gostaria de situar esta pesquisa.

Essa primeira aproximação, que reconhece as diferenças e aproxima questões consideradas fundamentais, permite um segundo movimento. Partindo da região do particular em que, segundo Pêcheux, se situa o discurso, entendido, portanto, como posição intermediária entre a língua e a história, coloco em questão o acontecimento tal como pensado pelo historiador e o acontecimento discursivo (PÊCHEUX, 2015 [1983]).

Para uma primeira abordagem, recorro a Pierre Nora (1988 [1974]) cujo trabalho, junto de Le Goff, trata, dentre outros temas, dos novos problemas da história.

Em O retorno do fato, Nora arrisca um lugar e uma identidade para a história do tempo presente. Defendendo que nenhuma época jamais teria visto, como a contemporânea à de sua escrita, o presente tão possuído de sentido histórico, afirma que isso já seria suficiente para "libertar a história contemporânea da sua imperfeição" 
(NORA, 1988 [1974], p. 180). Não me atenho, neste trabalho, ao menos diretamente, a essa discussão. Interessa-me a abordagem que Nora faz sobre o acontecimento para encontrar o lugar e a identidade da história do tempo presente.

Para dar conta do acontecimento do presente, próprio à história do presente, Nora não se esquiva buscá-lo em suas origens, no último terço do século XIX (cf. NORA, 1988 [1974], p. 180). Nesse ponto, vale a pena recorrer às suas próprias palavras, pois elas também tocam na discussão feita neste artigo:

Todo o trabalho dos positivistas consistiu precisamente, por um lado, em fundamentar a história no estudo do passado, cuidadosamente separado do presente, e, por outro, em movimentar esse passado por um encadeamento contínuo de "acontecimentos". [...]. Animada pela ambição de transportar para o campo das ciências sociais os métodos das ciências experimentais, essa equipe de historiadores não procurou senão atestar cientificamente um fato, reconstruí-lo pacientemente para retomar todo o passado através de uma série de acontecimentos constituídos por uma reunião de fatos, e remeter a descontinuidade de acontecimentos únicos à cadeia de uma casualidade contínua (NORA, 1988 [1974], p. 180).

Nos termos da discussão deste artigo, os positivistas de que fala Nora são os mesmos criticados por Aron, nos quais este autor detectava uma filosofia subjacente. Partindo de Aron e passando por Braudel, pode-se dizer que há uma recusa por parte da Escola dos Annales, guardadas as diferenças teóricas de cada um dos pesquisadores tidos como pertencentes a ela, do acontecimento tal como era tratado pelos positivistas e, também, uma recusa da narrativa (cf. BURKE, 2010, p. 12).

Neste ponto, é importante relembrar o lugar em que se inscreve o trabalho de Nora. O volume que organizou com Le Goff e que contém o capítulo aqui discutido tem como subtítulo "novos problemas" . Já no título, ao referir-se ao retorno do fato (retour de l'événement), Nora fala do retorno do acontecimento. Mas não do mesmo acontecimento de que tratavam os positivistas. O acontecimento a que Nora chama de moderno, abandonando o caráter de dignus est intrare (digno de fazer parte) que lhe foi conferido no século XIX, está relacionado com as mídias de massa e une um feixe de significações esparsas, de modo que,

\footnotetext{
${ }^{6}$ História: novos problemas (Parte 1); História: novas abordagens (Parte 2) e História: novos objetos (Parte 3), todos organizados por Le Goff e Nora. No Brasil, foram editados pela Francisco Alves, em 1976, dois anos após serem lançados na França, em volume único.
} 
ao historiador cabe desuni-los para voltar da evidência do acontecimento à colocação em evidência do sistema. Pois a unicidade para que se torne inteligível postula sempre a existência de uma série que a novidade faz surgir. [...]. Não há diferença de natureza entre uma crise, que é um complexo de acontecimentos, e um acontecimento, que assinala em algum lugar dentro do sistema social uma crise. (NORA, 1988 [1974], p. 191).

Com essa breve discussão, procuro mostrar, em três momentos distintos Positivismo, Annales e - na falta de classificação melhor, pois Nora e Le Goff são tidos como ainda pertencentes a Escola dos Annales - Novos problemas, o estatuto variado que o conceito de acontecimento assumiu na história, seja como motivo de uma prática, seja como elaboração teórica. Se, no fim século XIX, o acontecimento esteve ligado à razão histórica e, portanto, era quase sempre o acontecimento político, nos termos da discussão de Nora, ao ser recuperado do esquecimento imposto por certos pesquisadores dos Annales, assume o caráter de feixe de significações esparsas.

Diante do quadro discutido e das noções descritas, destaca-se a particularidade que faz do acontecimento discursivo (PÊCHEUX, 2015 [1983]) a mais adequada das noções para o tipo de pesquisa que empreendo. Antes de mais nada, note-se que o acontecimento discursivo não se confunde nem com a notícia, nem com o fato ligado ao poder e, portanto, não se confundiria com o acontecimento construído pelo historiador (GUILHAUMOU; MALDIDIER, 2014 [1986], p. 172), nem nos termos dos positivistas nem nos de Nora, embora, em relação a este último, haja uma aproximação possível. Para Guilhaumou e Maldidier (2014 [1986], p. 172), o acontecimento discursivo é "apreendido na consistência de enunciados que se entrecruzam em um dado momento". Ou, ainda, nos termos de Pêcheux (2015 [1983], p. 16), é o "ponto de encontro de uma memória e uma atualidade".

Justifico a escolha pelo acontecimento discursivo, numa pesquisa com um componente incontornavelmente histórico, em detrimento, por exemplo, do acontecimento do historiador. Em primeiro lugar, o acontecimento discursivo, nos termos de sua definição, põe o enunciado e, portanto, a língua como base de processos discursivos, em primeiro plano. Para uma análise que se pretende linguísticodiscursiva, esse é um dado fundamental, desde o momento da seleção do corpus. 
Ao considerar a relação entre as instâncias de produção/destinação/circulação de um livro escolar como acontecimento discursivo, os seus dados editoriais lacunares podem ser compreendidos, dentro do quadro teórico que busquei construir até o momento, como um dos enunciados que compõem esse acontecimento. Sua natureza lacunar, antes de ser um problema prático para a pesquisa, passa a ser uma característica dessa relação entre produção/destinação/circulação, cuja pertinência está no fato de que ela, junto de outros enunciados, constitui esse livro escolar que, embora não identificado com o acontecimento discursivo, é um artefato historicizado. O dado editorial, nesta perspectiva, é uma das ruínas que constituem esse acontecimento e, portanto, pode e deve ser considerado como tal para um procedimento teórico-metodológico consequente.

No lugar da impossibilidade de uma abordagem quantitativa em relação a esses dados editoriais, faço a opção por uma análise qualitativa para a operacionalização do critério autoral-editorial na seleção do corpus. Uma abordagem qualitativa e que considere os dados editorias como ruínas, não como dados quantitativos a serem recompostos, daria conta, por exemplo, de selecionar um material que, embora não represente o artefato com maior difusão, pode representar a sua inserção na história do livro escolar na qualidade de um acontecimento discursivo, portanto uma existência particular, a do acontecimento discursivo, entendido como a relação entre produção/destinação/circulação de um livro escolar.

\section{O caminho até as ruínas}

Embora recente em relação a outros países, como a França (cf. BITTENCOURT, 1993), a produção brasileira de livros didáticos, desde há muito tempo, é um dos mercados mais rentáveis. Considerada a situação do parque gráfico brasileiro de cada período de 1930 a 2002, isto é, o seu grau de desenvolvimento, é possível dizer que os livros didáticos foram quase sempre produzidos, desde que se considerem essas condições materiais da indústria do livro, em grande escala. 
Antes de abordar, portanto, o problema dos dados editoriais em ruína de grupos operacionalizáveis de livros escolares de português, abordo outro problema, também de natureza teórico-metodológica: como chegar a esses conjuntos operacionalizáveis, dentre inúmeros livros didáticos produzidos numa determinada década ou num determinado recorte temporal, sem deixar de levar em conta as exigências, sobretudo metodológicas, da pesquisa linguística cujo componente histórico é incontornável?

Para dar conta desse problema, o caminho que tomo, ao menos para a década de 1930, período de publicação do livro escolar escolhido para exemplificar a discussão teórica feita neste artigo, é perseguir certas políticas federais do livro didático. Destaco, portanto, a primeira lei do livro didático, promulgada no contexto do Estado Novo, durante a gestão de Gustavo Capanema no Ministério da Educação e Saúde, o decretolei no. 1006/1938, e, mais especificamente, a criação da Comissão Nacional do Livro Didático (CNLD), cuja função seria avaliar e autorizar livros didáticos a serem adotados no Brasil (FILGUEIRAS, 2013, p. 161).

Segundo Filgueiras (2013, p. 161), a Comissão Nacional do Livro Didático, apesar de entraves organizacionais, não só funcionou, como efetivamente avaliou livros didáticos e, imbuída de certa autoridade, pois contava com o apoio do Governo Federal e era composta, no período, por nomes importantes da educação primária, secundária e superior, pretendeu uniformizar os conteúdos e métodos desses livros. Desse modo, ainda segundo Filgueiras (2013, p. 161), é possível dizer que as discussões e embates em torno da CNLD influenciaram a constituição das disciplinas escolares.

O decreto-lei no. 1.006/1938, que, dentre outras coisas, criou a Comissão Nacional do Livro Didático, atribuiu suas funções e também especificou seu modo de funcionamento. Essa Comissão deveria avaliar e autorizar livros didáticos a serem usados no Brasil. Vale lembrar que avaliação e autorização, consideradas as contradições das políticas do Estado Novo, podiam guardar não só o aspecto da valoração técnica, mas também algum risco de exclusão político-ideológica. Em princípio, para essa avaliação, a Comissão contaria com sete membros, escolhidos pelo presidente da República, em função de suas especialidades para compor três áreas, a saber: metodologia das línguas, metodologia das ciências e metodologia das técnicas (FILGUEIRAS, 2013, p. 166). Os livros didáticos seriam analisados por um relator e dois 
revisores. Caso aprovado, receberia um número de registro e o informe "livro de uso autorizado pelo Ministério da Educação", que deveriam aparecer na capa (FILGUEIRAS, 2013, p. 167). Uma das funções da CNLD era, em janeiro de cada ano, divulgar, por meio do Ministério da Educação, no Diário Oficial, a relação dos livros didáticos de uso autorizado.

Após uma reestruturação mais efetiva por meio da portaria ministerial no. 253, de 24 de dezembro de 1940 (FILGUEIRAS, 2013, p. 172), a CNLD realizou sua primeira reunião em 14 de janeiro de 1941. De acordo com Filgueiras (2013, p. 172), até julho de 1941, dos 1.986 livros enviados para avaliação, 140 foram avaliados. Por esses números, pode-se ver que o funcionamento da CNLD não correspondia à velocidade das solicitações de avaliação. Planejada para o dia $1^{0}$ de janeiro de 1940, a divulgação da primeira relação de livros aprovados teve um longo atraso (sete anos).

A primeira lista de livros aprovados só foi publicada em setembro de 1947. Entre 1938 e 1947, houve mudanças na organização da CNLD e, mais importante, a consolidação da política do livro didático com o decreto-lei n. 846o/1945, proposto pelo então Ministro da Educação e Saúde, Raul Leitão da Cunha (DASSIE, 2012, p. 92). Como estão fora do escopo deste artigo, não discutirei essas mudanças, apenas destaco que, a partir da consolidação da política do livro didático e da Portaria n. 363 de 31 de julho de 1947, as relações de livros didáticos aprovados deveriam ser publicadas, no Diário Oficial, semestralmente. Essas publicações foram feitas de 1947 a 1961, com um intervalo entre 1947 e 1950 (DASSIE, 2012, p. 97).

Baseado no trabalho de Dassie (2012, p. 97, mais especificamente, Tabela 1), que, nessas publicações do Diário Oficial, de 1947 a 1961, fez um levantamento dos livros de matemática que foram aprovados, fiz um levantamento dos livros de português aprovados no mesmo período.

Na primeira lista publicada, em setembro de 1947, na seção de livros de português para o ensino secundário, aparece o Método de redação, de Carlos Góes, ao lado de mais três outros livros: Noções de análise sintática, de Artur Paupério, Sintaxe de construção, também de Carlos Góes e Idioma pátrio, de Modesto de Abreu.

Pode-se levantar a hipótese de que o Método, publicado em 1930, tenha sido submetido à avaliação anos antes de 1947, já que houve atraso de sete anos na 
publicação da primeira lista. $\mathrm{O}$ acesso a essas listas é importante porque permite a redução, no universo de livros publicados, a um certo número de publicações organizadas, avaliadas, aprovadas e que, pelo menos por hipótese, tiveram uma circulação razoável. Por mais que representem as exigências do poder instituído à época e também estejam bastante ligados aos currículos de ensino promulgados pelo Ministério da Educação, esses livros podem ser representativos para a pesquisa, pois, pelo próprio fato de terem sido normalizados pela CNLD, é possível buscar neles, enquanto parte de um acontecimento discursivo, o particular do discurso, que está entre a língua e a história e que, apesar da regulação institucional, escapa às imposições conscientes de avaliadores, ministros e outros atores do campo político ou pedagógico.

Com base nesse conjunto de intervenções metodológicas, a análise linguísticodiscursiva desses livros aparece como possibilidade e - mais importante para a discussão teórico-metodológica deste artigo - permite o trabalho com dados editoriais em ruína, ou seja, a partir de um conjunto de livros didáticos de português que cobre 72 anos de ensino, selecionar um corpus de oito livros.

\section{O Método de redação, de Carlos Góes}

Antes de me deter em dados editoriais particulares desse livro didático, analisoo em termos do que Bakhtin (2016 [1978], p. 12) propõe como elementos constituintes do gênero discursivo, a saber, conteúdo temático, estilo e construção composicional.

Carlos Góes, em Método de redação com vocabulário e gramática aplicada, destaca sua atuação como professor em detrimento de sua carreira como filólogo ou escritor. No centro de sua proposta, está a urgência de contrapor o "processo geralmente adotado" no ensino da redação ao seu método, fruto de quinze anos de trabalho no Ginásio Oficial de Minas, em Belo Horizonte. O ensino de escrita, tido como um dos problemas mais sérios para os professores, consistia, nesse momento, para Góes, num procedimento que, com alguma variação, resumia-se a um encadeamento de pequenas atividades sem resultado. 
O tempo gasto com as correções - não remunerado, destaca Góes -, associado ao pouco efeito que ela surtiria nos grupos de alunos, é apontado como resultado de observação que sua carreira lhe proporcionou e, em decorrência disso, deram ensejo ao seu método, tão oposto ao que ele chama tradicional.

O método apresentado por Carlos Góes tem como eixo orientador algo semelhante ao que, mais recentemente, tem sido chamado de reescrita: na seção do Método chamada Como pôr em prática o método de redação? (1930, p. 2), o autor recomenda o seguinte procedimento: um aluno seria convidado pelo professor a escrever no quadro negro um modelo e também as indicações de vocabulário e gramática aplicada; os demais alunos deveriam copiar o trecho (ou prova) do quadro e, posteriormente, como tarefa extraescolar, reescrever esse modelo em uma folha destacada do caderno, observando sempre as orientações dadas durante a aula. No caso, por exemplo, de um modelo de carta de admoestação, escrito na $2^{\mathrm{a}}$. pessoa do singular, a atividade seria passá-la para a $2^{\underline{\underline{a}}}$ pessoa do plural e, também, substituir os vocábulos destacados pelos que apareciam no vocabulário da proposta. Portanto, "o alumno reproduzirá por outras palavras a prova primitiva” (GÓES, 1930, p. 2).

Os critérios de sucesso elencados pelo autor são, em primeiro lugar e mais uma vez, sua experiência didática empírica (GOES, 1930, p. 4-5) com o próprio método; em segundo lugar, o que é de grande interesse, os exames admissionais para o ensino superior: "as provas dos gymnasianos eram sempre as melhores, sobresahindo das demais pela relativa precisão vocabular, pontuação, orthographia e syntaxe” (GÓES, 1930, p. 5). Insistindo nas provas admissionais, o autor convoca um "ilustre lente da Faculdade de Direito" (GÓES, 1930, p. 5), que dizia reconhecer os alunos do Ginásio Oficial de Minas - do qual Góes era professor - pela escrita tão característica.

A oposição entre um método tradicional e um método inovador, calcado na ideia de que a modernidade, no século XX, daria conta do atraso de um Brasil imperial, é resumida no aforismo “o máximo resultado com o mínimo esforço” (GÓES, 1930, p. 5), destacado pelo autor.

Na década de 1930, primeiros anos de "consolidação" da escola republicana, já se esboçam elementos que seriam constitutivos de toda a escolarização brasileira e, especialmente, do ensino da escrita; a preocupação com os exames admissionais para o 
ensino superior, cuja aproximação com os atuais vestibulares seria possível se tratada em termos de um dado em estado de ruína, já se desenhava, por exemplo, como definidora da postura diante do ensino de português. Por outro lado, há particularidades, como a preocupação com o estilo. Entre os supostos métodos tradicional e inovador, há nuances que também são pertinentes para o estudo do ensino da escrita. Recorde-se, a propósito, de que todo acontecimento, tido como novidade ${ }^{7}$, carrega em si repetições da história (cf. COURTINE, 2014 [1981] e PÊCHEUX, 2015 [1983]).

No livro de Carlos Góes, os exercícios têm algo que os vincula enquanto unidade:

Figura 1: Reprodução do primeiro modelo do Método.

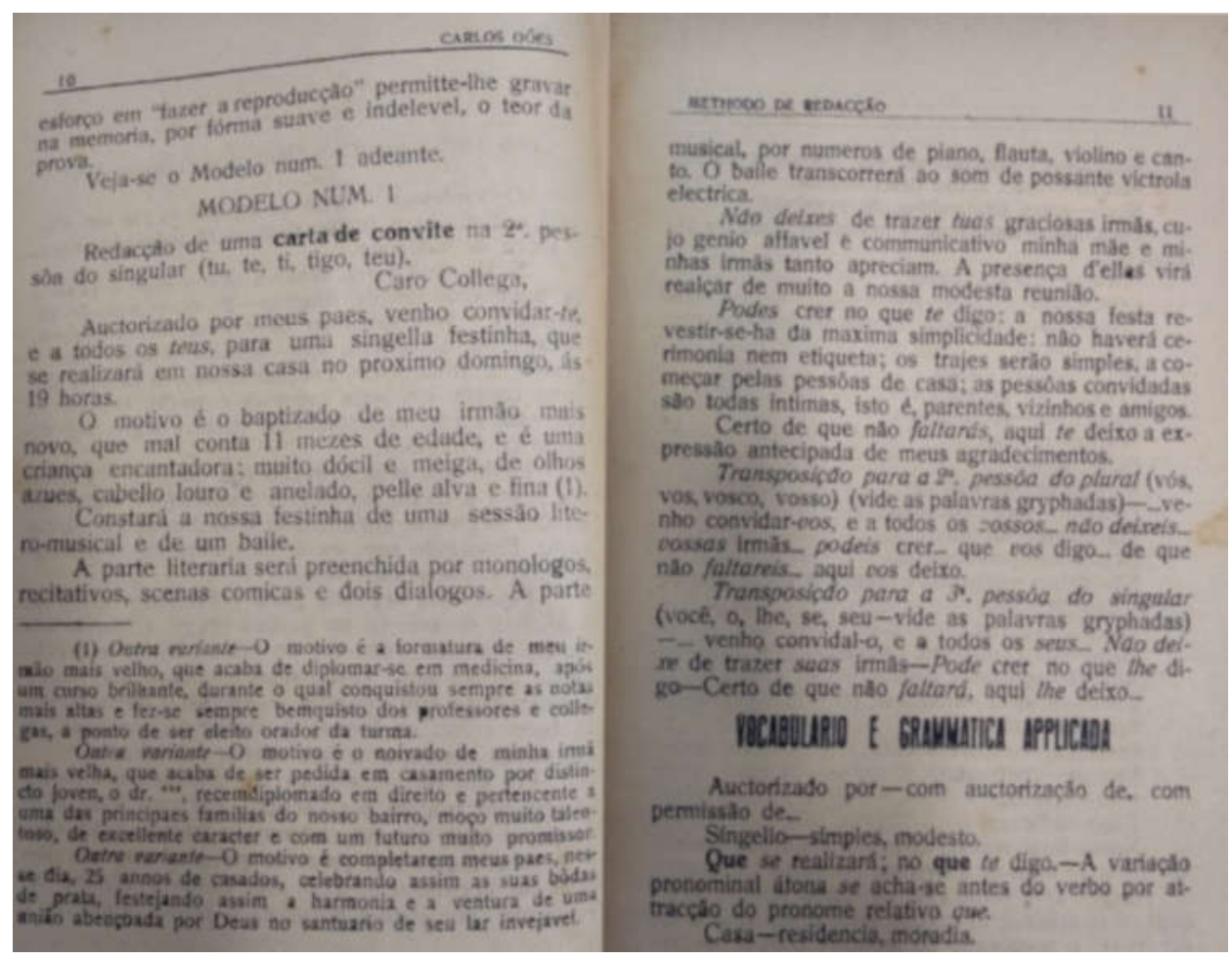

Fonte: Biblioteca do Livro Didático da USP.

\footnotetext{
${ }^{7}$ Conferir, em artigos que, da mesma perspectiva teórica, discutem a produção escrita do ponto de vista dos critérios da experiência da adequação e da novidade do acontecimento, a exemplo de Corrêa (2006a).
} 
Nenhum dos exercícios tem instruções específicas sobre a estrutura do gênero abordado, somente um modelo e uma série de questões sobre vocabulário e gramática, como o título "vocabulário e gramática aplicada" sugere (cf. Figura 1). Predominantemente, os modelos apresentados são cartas. Além do caráter beletrista na escolha desse modelo ${ }^{8}$, pode-se considerar um aspecto da injunção ao dizer por meio desse recurso. Conhecer o aluno por meio dessa injunção ao dizer pode significar não apenas promover a recomendada integração enquanto sujeito histórico, mas, sobretudo, substituir modos de existência por modelos de comportamento e relacionamento nem sempre historicamente justificáveis.

Os exercícios consistem, geralmente, na passagem de uma pessoa verbal para outra e substituição de palavras a partir do vocabulário indicado, procedimento que só reforça, no entanto, a reprodução do modelo. Seu caráter beletrista é associado à injunção ao dizer. Vejamos:

\section{Caro collega,}

Venho trazer-lhe a expressão sincera de meu profundo pesar pelo rude golpe, que o destino acaba de desferir-lhe, privando-o de um ente, que lhe era tão caro e affeiçoado, e cuja perda abre em sua vida um claro impreenchivel.

[...]

Entretanto posso affirmar-lhe que participo sinceramente de sua intensa magoa, por isso que muito estimava seu pae, já pelo tom delicado de sua palestra, sempre fértil em bons conselhos; já por sua nórma de vida austera e irreprehensivel; já pela confiança que depositava em mim, consentindo que eu fosse um dos raros companheiros junto a Você, cioso como era de escolher, elle proprio, as affeições para seus filhos. Eu era uma d'essas affeições: isso muito me elevava e dignificava (GÓES, 1930, p. 18-19, grifos do autor).

Pode-se mostrar a ênfase na expressividade do sujeito característica de certa concepção de estilo, por exemplo, pela presença quase categórica de adjetivo, frequentemente anteposto. Dos seis sintagmas nominais que aparecem no primeiro parágrafo, quatro apresentam adjetivo, dois deles antepostos e dois pospostos: “a expressão sincera", "de meu profundo pesar", "pelo rude golpe” e "um claro

\footnotetext{
${ }^{8} \mathrm{~A}$ presença das cartas poderia indicar uma primeira pista sobre a concepção de linguagem, escrita e ensino de escrita em jogo: beletrista e voltada aos clássicos (SOARES, 2002), isso porque a carta, na Idade Média, representou, enquanto gênero, a retomada dos clássicos greco-romanos e se tornou matéria de ensino. Foi nesse período que surgiram as Ars Dictaminis, que defendiam uma divisão da epístola em cinco partes: salutatio, benevolentiae captatio, narratio, petitio e conclusio (SCABIN, 2010, p. 4).
} 
impreenchivel". Considere-se, ainda, que o mesmo parágrafo apresenta uma oração relativa ("que lhe era tão caro e afetuoso"), em que o predicativo se especifica em coordenação de grupos adjetivos ("tão caro e afetuoso"). A esse modo de construção, alia-se, em termos sintáticos, a ênfase em construções marcadas por escolhas próximas ao que, na oratória, constituiria um estilo elevado dirigido a um auditório erudito ou cuja expressão adequada fosse considerada como apropriada a saberes comportamentais supostos como adequados a esse tipo de público. Note-se, no terceiro parágrafo do modelo, um exemplo dessas escolhas:

Participo sinceramente de sua intensa magoa, por isso que muito estimava seu pae, já pelo tom delicado de sua palestra, sempre fértil em bons conselhos; já por sua nórma de vida austera e irreprehensivel; já pela confiança que depositava em mim, consentindo que eu fosse um dos raros companheiros junto a Você (GÓES, 1930, p. 19, grifo meu).

Nesse exemplo, as partes destacadas mostram o uso de construção causal introduzida por uma locução conjuntiva de efeito (por isso que), seguida por uma enumeração, feita à maneira dos “considerandos”, e introduzida por “já por/já pelo(a)”. Constata-se, assim, um estilo beletrista, calcado, provavelmente, em gêneros do campo jurídico, que combina construções morfossintáticas (no nível do sintagma nominal e do grupo adjetivo) e construções no plano propriamente sintático, estilo todo ele elaborado em função de fazer-se marcar como empático a uma situação de perda (trata-se de uma carta de pêsames), sem que isto impeça de introduzir, para o destinatário, padrões de comportamento tais como: "já pela confiança que depositava em mim, consentindo que eu fosse um dos raros companheiros junto a Você, cioso como era de escolher, elle proprio, as affeições para seus filhos" (GÓES, 1930, p. 19, grifo meu).

A proeminência desses elementos parece indicar que o estilo, em detrimento da construção composicional ou do conteúdo temático - que atuam, os três, em conjunto, segundo Bakhtin (2016 [1978]) -, foi privilegiado por Góes. Embora se pudesse objetar que o estilo se volta à estilística tradicional, é possível - num esforço de leitura dialógica aplicada ao material - pensar no estilo proposto segundo uma concepção bakhtiniana, pois a decisão do autor parece replicar à concepção de estilo dominante 
naquele momento, em que, na produção oral, se prezava muito a oratória e, no registro gráfico, a sua contraparte, a escrita emplumada.

As condições sócio-históricas determinaram o privilégio a esse modo de ensino de escrita e isso tem efeitos no modo como a escrita e seu ensino foram concebidos e, sobretudo, no modo como essa concepção travou relações com outras formas de se conceber escrita e seu ensino. Considerando-se o discurso pedagógico que orienta a escolha do estilo como elemento privilegiado, pode-se dizer, em termos bakhtinianos, que a opção do autor deu-se segundo o aspecto dialógico do estilo, produzido sempre a dois (BAKHTIN, 2016 [1978]). No caso, uma proposta pedagógica (a de Carlos Góes) que replica a um modo de conceber a "boa" fala e a "boa" escrita.

Interessa, ainda, pensar que, dentre outras coisas, o destaque para o uso estilístico da língua encontra motivação na mesma justificativa que, num movimento dialógico, deu lugar, primeiramente, ao português como matéria escolar. A República incipiente precisava se firmar como nação e a língua foi uma das vias escolhidas, como exemplifica Hansen (2009, p. 42-43) ao remeter-se ao papel da literatura cívica quando comenta o desenvolvimento da literatura infantil e de uma concepção de criança mais ou menos no mesmo período, afirmando “o engajamento próprio dos autores desses textos nas questões de seu tempo" e a articulação desse engajamento com o "papel assumido por muitos intelectuais atuantes no contexto das transformações ocorridas na passagem do século XIX para o XX”.

\section{Análise e resultados dos dados em ruína}

Consideradas essas observações analíticas, percebe-se que o livro escolar de Góes oferece subsídios informacionais e teóricos suficientes para compor o material desta pesquisa. No entanto, é necessário, para finalizar, dar conta do critério autoraleditorial, que, segundo a discussão teórica feita, consiste em considerar os dados editoriais como enunciados em ruína que compõem a relação entre 
produção/destinação/circulação do livro didático entendida como acontecimento discursivo.

Num levantamento pouco criterioso no site Estante Virtual, que reúne sebos de diferentes locais do país, encontrei 8 volumes de, no mínimo, 5 edições diferentes do Método: apareceram, em sebos de São Paulo, Belo Horizonte, Peruíbe, Varginha e

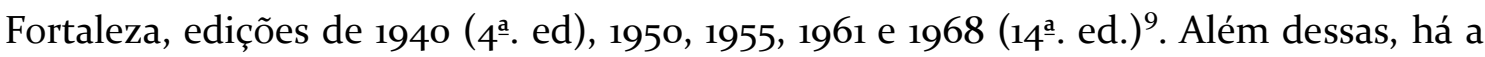
edição com que trabalho, de 1930, disponível na Biblioteca de Livros Didáticos, da Faculdade de Educação (FE), da Universidade de São Paulo.

Embora esse levantamento não tenha a validade de um documento oficial, permite supor a existência de um número bastante significativo de edições do Método. Dessa constatação, tiro, ao menos, duas considerações fundamentais. A primeira, e mais importante, seria o fato de que, de 1930 a 1968, o livro teve, no mínimo, 14 reedições. É um dado vago, pois não sabemos as tiragens de cada edição, no entanto, não deixa de atestar sua circulação e, ainda, sua longevidade (no mínimo, 38 anos). A segunda é que, hoje, ele está disponível em diferentes regiões do País, revelando um pouco de sua circulação em termos geográficos, ainda que de forma fragmentária e pouco definitiva.

Comparando a edição disponível para consulta na Biblioteca de Livros Didáticos da FE/USP com as que estão à venda nesses diferentes sebos, chega-se a um ponto particularmente relevante para esta discussão, que pretende determinar a importância e circulação de certo livro escolar de português considerada a relação entre produção/destinação/circulação como acontecimento discursivo e seus dados editoriais lacunares como enunciados que compõem esse acontecimento, evidenciando que a fundamentação teórico-metodológica atua desde o primeiro momento da pesquisa.

Nessa edição, datada de 1930, a editora responsável pela publicação do Método de redação já é a Paulo Azevedo \& Companhia, razão social, da década de 1920 em diante, da editora Francisco Alves.

O que, a princípio, pode ser a mera constatação da casa editorial pela qual o livro publicado, informa, no entanto, muito sobre a circulação de uma obra. redacao/2976295484>. Acesso em: 08 de mar. 2018. Considere-se, nesta pesquisa, o caráter aberto (e pouco preciso) das inserções e exclusões diárias de volumes e edições. 
Bittencourt (1993, p. 81), ao tratar da relação das editoras com o poder institucional, menciona que a Francisco Alves foi a primeira grande editora de didáticos. Mais interessante, afirma que, para consolidar sua expansão, comprava os direitos de obras de sucesso editorial e fazia, em revistas e jornais, grande alarde sobre essas compras (BITTENCOURT, 1993, p. 83).

Dessa estratégia agressiva de mercado, pode-se levantar uma hipótese. Se um livro didático era publicado pela Francisco Alves, havia grandes chances de ser um sucesso de vendas. A exemplo disso, basta olhar para as gramáticas de João Ribeiro, que tiveram várias reedições com grandes tiragens. Note-se que não significa dizer que todos os livros didáticos publicados pela Francisco Alves eram sucessos editoriais, mas que, em função da estratégia de mercado da editora, é possível levantar a hipótese de que, no mínimo, Góes e seu livro eram relevantes nos círculos editoriais do período. Um outro dado que pode fortalecer a hipótese é o fato de o autor ter publicado outros textos pela mesma editora, como o Dicionário de Afixos e desinências, também de 1930 e igualmente destinado ao curso secundário, e o Dicionário de Galicismos, de $1929^{10}$.

A respeito da tiragem, recorro a Hallewell (1985, p. 216-217) para levantar uma outra hipótese. O autor, em capítulo dedicado à editora Francisco Alves, apresenta algumas informações sobre os custos e tiragens de um livro didático típico editado por essa casa editorial, a Cartilha da infância, de Thomaz Galhardo. Para isso, baseia-se em dados fornecidos por Monteiro Lobato numa de suas cartas, na qual faz comentários sobre os custos da produção dessa cartilha, e numa análise de atividade editorial feita pelo Estado de S. Paulo, reproduzida na Revista do Brasil, em março de 1921. Lobato não indica a tiragem do livro em questão, mas a análise do Estado informa que, para didáticos, ela costumava variar entre cinco mil e cinquenta mil exemplares, o que faz Hallawell (1985, p. 216) supor que a cartilha teve uma tiragem de vinte mil exemplares, pois "era uma obra amplamente adotada”.

\footnotetext{
${ }^{10}$ Em carta endereçada ao diretor do Instituto Nacional de Estudos Pedagógicos (INEP), Lourenço Filho, em 7 de dezembro de 1942, Antenor Araujo Vianna solicita uma relação dos "livros de gramática adotados nos cursos primário, admissão, ginasial, normal, secundário do Brasil”. Lourenço Filho remete a ele uma lista com mais de 150 livros de português, divididos por título, autor e editora. Nesta lista, pela Francisco Alves, constam 7 livros de Carlos Góes, incluído o Método de redação. Dentre os autores da casa, ele é o que mais tem livros publicados (Carta do Acervo Histórico do Inep, disponibilizada pelos funcionários do Centro de Informação e Biblioteca em Educação, nomeadamente, Raphael Vinícius da Costa e a Brenda Narjara, aos quais agradeço).
} 
Voltando ao Manual de redação, proponho os seguintes ajustes: ele foi publicado em 1930 e trata-se de um livro didático destinado ao ensino secundário. Em 1930, a Francisco Alves começava a perder seu espaço no mercado de didáticos, pois esse é o período de ascensão da Companhia Editora Nacional no segmento (cf. HALLEWELL, 1985, p. 219). Entretanto, mesmo com essa queda, ela continua a ocupar o segundo lugar. Disso, levanto a hipótese de que a tiragem de didáticos continuava sendo alta, variando entre cinco mil e, talvez, um pouco menos de cinquenta mil exemplares. Como o livro de Góes é voltado para o ensino secundário, publicado ainda antes da reforma Campos, de 1931, que trabalhou na expansão desse sistema, é provável que sua tiragem seja menor que a da Cartilha, analisada por Monteiro Lobato e, anos mais tarde, por Hallewell, que era destinada ao ensino primário, já consideravelmente expandido na década de 1930 e, ainda segundo Hallewell (1985, p. 288-289), o principal público da Francisco Alves. Não me arrisco a propor um número, como fez Hallewell, mas não deixo de pontuar que, considerados esses dados, ainda que dispersos (enunciados em ruína), é possível dizer que o livro de Góes foi representativo de uma década, a de 1930.

Ora, com essas informações, não é, portanto, absurdo sugerir a seguinte hipótese: sendo publicado pela Francisco Alves num período ainda de participação intensa no mercado de didáticos, foi um livro relevante para seus contemporâneos, tanto que seus editores o submeteram aos órgãos reguladores do governo quando foi necessário, como à CNLD, e continuaram a publicá-lo, pelo menos, até o fim da década de 1960. A partir dessa hipótese, associada aos outros dados mencionados, por mais lacunares que eles sejam, é possível, com alguma garantia, falar sobre uma circulação significativa do Método de redação e, portanto, cumprir com o critério autoral-editorial para seleção do corpus desta pesquisa, desde que o livro escolar seja considerado um artefato historicizado, parte do acontecimento discursivo da sua produção (ponto de partida) e de sua destinação (ponto de chegada).

\section{Considerações finais}


Com a análise do Método de Redação, de Carlos Góes (1930), em que sublinho dados editoriais em ruína, procurei mostrar sua importância em função de sua presença em sebos de diferentes lugares do país e, principalmente, de sua longa carreira na editora Francisco Alves/Paulo Azevedo \& Cia., tão importante à época. Por esse recurso teórico-metodológico, foi possível incluí-lo dentre os documentos a serem considerados na pesquisa de mestrado, em andamento.

Como ficou explicitado no percurso deste trabalho, a discussão teórica proposta é um dos primeiros passos em direção a uma análise linguístico-discursiva de um conjunto de oito livros didáticos de português produzidos entre 1930 e 2002. Considerada essa aproximação entre história e linguística (mais particularmente, de linguística aplicada de uma perspectiva discursiva), é possível, dentro do quadro teórico eleito, contribuir com o campo da linguística aplicada e, em diálogo com o da história, capturar, nos desenvolvimentos em processo na pesquisa maior de que este trabalho faz parte, concepções de língua, de escrita e de ensino de escrita e suas marcas sócio-históricas.

\section{Referências}

BAKHTIN, Mikhail. Os gêneros do discurso. Tradução de Paulo Bezerra. São Paulo: Editora 34, 2016 [1978].

BITTENCOURT, Circe. Livro didático e conhecimento histórico: uma história do saber escolar. 1993. Tese (Doutorado em História Social) - Faculdade de Filosofia, Letras e Ciências Humanas, Universidade de São Paulo, São Paulo, 1993.

BURKE, Peter. A Escola dos Annales (1929-1989): a revolução francesa da historiografia. Tradução de Nilo Odalia. São Paulo: Editora Unesp, 2010.

CERTEAU, Michel de. A operação historiográfica. In: CERTEAU, Michel de. A escrita da história. Tradução de Maria de Lourdes Menezes. Rio de Janeiro: Forense Universitária, 1982 [1974]. p. 65-122. 
CORRÊA, Manoel. Heterogeneidade da escrita: a novidade da adequação e a experiência do acontecimento. Filologia e Língua Portuguesa, São Paulo, n. 8, p. 269296, $2006 a$.

. Relações intergenéricas na análise indiciária de textos escritos. Trab. Ling. Aplic., Campinas, v. 45, n. 2, p. 205-224, 2006b.

COURTINE, Jean-Jacques. Análise do discurso político: o discurso comunista endereçado aos cristãos. Tradução de Cristina de Campos et al. São Carlos: EDUFSCar, 2014 [1981].

DASSIE, Bruno. A Comissão Nacional do Livro Didático após 1945 e os livros de matemática aprovados para uso no ensino secundário. Revista HISTEDBR On-line, Campinas, n. 47, p. 88-107, 2012.

FILGUEIRAS, Juliana. As avaliações dos livros didáticos na Comissão Nacional do Livro Didático: a conformação dos saberes escolares nos anos 1940. Rev. bras. hist. educ., Campinas, v. 31, n. 1, p. 159-192, 2013.

GÓES, Carlos. Methodo de redacção. Com vocabulario e grammatica applicada. Belo Horizonte/São Paulo/Rio de Janeiro: Paulo Azevedo \& Comp., 1930.

GUILHAUMOU, Jacques; MALDIDIER, Denise. Efeitos do arquivo: a análise do discurso ao lado da história. In: ORLANDI, Eni (Org). Gestos de leitura da história no discurso. Tradução de Suzy Lagazzi e José Nunes. Campinas: Unicamp, 2015[1986]. p. 169-192.

HALLEWELL, Lawrence. O livro no Brasil: sua história. Tradução de Maria Villalobos e Lólio Lourenço de Oliveira. São Paulo: EDUSP/T. A. Queiroz, 1985.

HANSEN, Patrícia. Brasil, um país novo. Literatura cívico-pedagógica e a construção de um ideal de infância brasileira na Primeira República. 2009. Tese (Doutorado em História Social) - Faculdade de Filosofia, Letras e Ciências Humanas, Universidade de São Paulo, São Paulo, 2009.

NORA, Pierre. O retorno do fato. In: LE GOFF, Jacques; NORA, Pierre. História: novos problemas. Rio de Janeiro: Francisco Alves, 1988 [1974]. p. 179-192.

PÊCHEUX, Michel. Análise automática do discurso. In: GADET, Françoise; HAK, Tony. Por uma análise automática do discurso. Tradução de Eni Orlandi. Campinas: Unicamp, 2010 [1969], p. 59-158. 
. Discurso: estrutura ou acontecimento. Tradução de Eni Orlandi. Campinas: Pontes, 2015 [1983].

- Semântica e discurso: uma crítica à afirmação do óbvio. Tradução de Eni Orlandi et al. Campinas: Unicamp, 2014 [1975].

SCABIN, Rafael. As cartas jesuíticas do século XVI e a Ars dictaminis medieval: uma proposta de leitura documental. In: Jornada de Estudos antigos e medievais, 9., Anais... Londrina: UEM, 2010. p. 1-10.

SOARES, Magda. Português na escola. Uma disciplina curricular. In: BAGNO, Marcos. (Org.). Linguística da Norma. São Paulo: Loyola, 2004. p. 155-177.

Recebido em 25/07/2018.

Aprovado em 22/11/2018. 